\title{
ACHIEVING A GOAL OF DISTINCTION IN YOUR DRESS
}

\author{
P. Osei-Poku and J. Adu-Agyem \\ Department of General Art Studies, \\ Kwame Nkrumah University of Science and Technology, Kumasi, Ghana
}

\begin{abstract}
The aim of this paper is to identify the essential and vital information about body proportions, body assets and body liabilities so as to realize the good features to emphasize and the flaws to improve through effective optical illusions in clothing. This study was based on the premise that many people disregard their proportions and figure types and just go for any style of dress that may not befit them. In order to achieve the above aim, pertinent literature was reviewed, and interviews conducted to investigate whether or not people consciously select their clothes on the basis of their body proportions. Thirty (30) ladies were interviewed and observed. The result was that the population studied was not individualistic in their dresses. The people had diverse criteria for selecting their clothes which largely excluded consideration of their body proportions. In discussing the results, personality analysis chart was designed for use of fashion conscious persons. This is in relation to the proportions of identified fashion models, average figures and some philosophy on ideal beauty. Besides, design elements which serve as effective tools for optical illusions and recommended design ideas for shaping selected figures have been provided to guide people to go for the most appropriate dress styles that are distinct and individualistic.
\end{abstract}

Keywords: Proportion, personality analysis, optical illusion, distinct dressing.

\section{INTRODUCTION}

It is important to achieve a goal of distinction in dressing. Distinction, in the context of this study, means individuality: dressing in the manner which will flatter a figure and express the wearer's temperament and personality. Knowing how to make the most of your looks means knowing yourself, studying your physical and personality characteristics so that you can make your clothes work for you. Studies have shown that generally people want to look good in their appearances, but they do not know the right outfits that are suitable for their body proportions and figure types. Some of the common complaints are "my legs are too skinny"; "I am thin and flat chested"; "my shoulders are too broad"; 
"my waist is very large" etc. These proportion problems justify that clothes should be carefully selected to harmonize with the wearer's silhouette or shape. Ideal silhouette is a unique system of analyzing figure proportionality and identifying styles that are flattering, pleasing and satisfying.

Most fashion mistakes happen when garments are chosen because of the way they appear "beautifully" on fashion models, dummies and/ or friends. Such mistakes can convey uncertainty and confusion in the look of the wearer. Making sure that your clothing fits you properly is the first step in dressing for success. Proper fit means appropriate size, shape, style and colour. In choosing the right clothing, the following six key points are very significant for consideration (Corley, 2007):

- Know your body shape

- Evaluate yourself; know which physical characteristics you should emphasize and which you should not.

- Determine your personal assets and liabilities; do you have a long neck? Short waist?

- Examine how your clothes fit; how each item fits you.

- Try on clothes from your wardrobe.

- What looks best on you?

Good appearance also builds morale, helps us to maintain our self respect and is important in achieving success in our competitive system whether we are competing in the social, political, economic or marriage market (Hazen, 1998). Without a doubt, clothing is the most prominent façade of our well being in the society. It can camouflage, it can cover up and it can build as much as it can destroy our image (Noubikko, 2007). Whether it is fair or not, a person's first judgment of the other is based on clothing. The rest including intellectual appreciation comes only second. Jackson (1980) indicates that few people have the perfect proportions that would allow them to wear almost any- thing, but they can create the illusion of average proportion by applying fashion illusion to allow the eye to see good appearances and minimize body faults.

The scope of this paper is concerned primarily with ladies clothes although some of the guiding principles are applicable to men's wear and other categories of outfits. For instance, optical illusion is generally employed in designs for both males and females, including casual wear, traditional wear, formal wear, bridal wear, children's wear, sports wear, evening wear, etc. Females have been used for the research because they are more fashion conscious than their male counterparts and they are also very much engrossed in clothing and attraction. Ladies outfits have a lot of intricate designs which can camouflage or build an image appropriately. Besides, figure proportions of females normally transform as a result of reproduction or procreation. This transformation, coupled with lack of regular physical exercises, often creates imbalance in their physique, some of which need critical examination for enhanced designs.

\section{MATERIALS AND METHODS Data Collection}

Data needed for the study were collected from both primary and secondary sources. A review of pertinent literature was done. An interview guide was designed and administered for the collection of the primary data. Thirty (30) ladies were randomly selected for interview. They were made up of students, teachers, administrators, business women, nurses and bankers. The interview was conducted to find out whether or not the 30 respondents have any knowledge of themselves in terms of their body measurements, proportions, assets and liabilities. Besides, do they have any criteria for selecting their clothes? Furthermore, an observational survey was conducted vigorously to find out the various shapes the selected population had in their individual figures. 


\section{RESULTS}

Starting with knowledge of body measurements, $5(16.67 \%)$ respondents claimed to have some knowledge of them whilst $25(83.33 \%)$ respondents did not have any idea. On figure proportions, only $4(13.33 \%)$ respondents said they understood their proportions whilst as many as $26(86.67 \%)$ did not have the slightest idea. Generally, it is certainly necessary for one to know his/her body measurements so as to reduce the mistakes of buying ill-fitted outfits. It is even more helpful for individuals, especially, females to understand their proportions as these are the key to dressing themselves to their best advantage.

Also, $6(20 \%)$ respondents could identify their body problems or liabilities as opposed to a high $24(80 \%)$ who responded negatively. It was also realized that $14(46.67 \%)$ respondents could identify their body assets but $16(53.33 \%)$ could not. Interestingly, all the $30(100 \%)$ respondents were of the view that selecting appropriate dress style should be considered very important. This is a positive signal which attests to the fact that wearers want to look good in appearance but there is inadequate knowledge in achieving this goal.

Finally, on the question of criteria they use in selecting their clothes, $10(33.32 \%)$ of the respondents declared that they consider designs that look nice on models or dress stands. This was followed by $8(26.73 \%)$ opting for designs that come with their (respondents') favourite colours and another $8(26.73 \%)$ going for designs that are in vogue. The least selected criteria, namely, designers' choice and expensive designs each had 2 $(6.67 \%)$ respondents opting for it. On the whole, the responses give the impression that the population studied has different reasons for selecting particular apparel and leaving the other (Table 1). Readers may also have their own criteria which may be similar to or different from the ones above but whatever the reasons are the bottom line is that they should go with their figure proportions.

Table 1: Knowledge about costume selection

\begin{tabular}{llc}
\hline Parameter Assessed & Responses & No. (\%) \\
\hline Body measurements & Yes & $5(16.67)$ \\
& No & $25(83.33)$ \\
Figure proportions & Yes & $4(13.33)$ \\
& No & $26(86.67)$ \\
Body liabilities & Yes & $6(20.00)$ \\
& No & $24(80.00)$ \\
Body assets & Yes & $14(46.67)$ \\
& No & $16(53.33)$ \\
Choice of appropriate dress style & Very important & $30(100)$ \\
& Not important & $0(0)$ \\
Selection of clothes & & $2(6.67)$ \\
& Designers' choice & $8(26.67)$ \\
& Taste for colours & $10(33.32)$ \\
& Models' beauty & $2(6.67)$ \\
& Expensive designs & $8(26.67)$ \\
\hline
\end{tabular}




\section{Observational Survey}

In observing the figure types of the population studied, the following descriptions give an indication of the differences among them:

1. Three (3) figures had a well-balanced shape with bust and hip circumference being similar and waist being smaller.

2. In nine (9) of the figures, shoulders were smaller than the hips. Weight was visualized to be concentrated at the hips and thigh areas.

3. Eight (8) figures had their bust looking larger than their hips.

4. Five (5) figures had their busts, waists and hips circumference almost equal. Out of these, one (1) was slender, two (2) heavy and another two (2) average.

5. Two (2) figures had full busts and hips but their waists were smaller in comparison.

6. Three (3) figures had large busts with thick waists and hips but their legs appeared to be slimmer.

\section{DISCUSSION}

It is established in this study that all fashion conscious people should do personal analysis to have ideas of their individual body measurements, proportions, assets and liabilities in order to determine the distinct dress to wear. However, to evaluate personal figure assets and problems it is helpful to compare one's measurements with identified fashion models and average figures so as to ascertain whether the person is well proportioned or not.
Natural History Magazine (1980) gives an estimation of an average girl between the ages of 20-24 years and a high fashion girl with the age 23.5 years. Women's Measurements for Garment and Pattern Construction (1985) also documents estimated measurements of an average woman. The two estimations are done in terms of weight, height, bust, waist, hip, thigh, calf and ankle as shown in Table 2. Comparing the three figures, a high fashion girl is the tallest, slimmest and lightest. The average woman is heaviest in weight. It should be noted that a good figure is not so much a matter of actual height and weight as of good proportion. In such pleasing proportioned figures, there should also be rhythmic gradation of restrained curves.

Although the three categories of figure measurements may seem remote, these forms and similar ones have been carried through several generations and used world wide as models of beauty. We entertain ourselves with various local, national and international beauty contests and shows such as Miss. Ghana, Ghana's Most Beautiful, Miss Universe, Miss World etc. Besides, when asked to name a beautiful celebrity or personality, we tend to respond with the same answers (i.e. slenderized, well shaped figures). This is certain because we imagine the same standard that is preset in our minds.

Jackson (1980) also holds the view that ideally, shoulders should be just an inch wider than the hips to allow the lines in the clothes to fall loosely over the hips from the shoulders. Therefore, if the

Table 2: Figure measurements for average girl, high fashion girl and average woman

\begin{tabular}{|c|c|c|c|}
\hline Figure & Average girl & High fashion girl & Average woman \\
\hline Weight & 123 Ibs. & 133.48 Ibs. & 120.1 Ibs. \\
\hline Height & $5 ' 3.6^{\prime \prime}$ & 5'3.16" & $5^{\prime} 7.75^{\prime \prime}$ \\
\hline Bust & $33.9^{\prime \prime}$ & $35.62 "$ & $33.6 "$ \\
\hline Waist & $26.4 "$ & $29.15^{\prime \prime}$ & $24.1 "$ \\
\hline Hip & $37.4^{\prime \prime}$ & $38.82^{\prime \prime}$ & $34.7^{\prime \prime}$ \\
\hline Thigh & $21.6^{\prime \prime}$ & $22.24 "$ & 19.3" \\
\hline Calf & $13.3^{\prime \prime}$ & $13.45^{\prime \prime}$ & $12.6^{\prime \prime}$ \\
\hline Ankle & $9.2^{\prime \prime}$ & $9.31^{\prime \prime}$ & $8.1 "$ \\
\hline
\end{tabular}

136 Journal of Science and Technology, Vol. 28, No. 2, August, 2008 
hips are more than an inch wider than the shoulders, or vice versa, the need to take steps to give the illusion of a better proportion is imperative. The average leg length is half of the entire height. If measurements reveal a discrepancy of more than an inch either way, there will be the need to use some camouflage, though slightly longer legs are often pleasing. The wellpositioned waist falls in the middle between the armpit and the point where the thigh joint "breaks" from the hip and a variation of more than an inch defines a person as either highwaisted or low-waisted.

It is worthy of note that ideals of beauty are very dynamic because the general taste of people also changes and can be examined in the light of their beliefs, culture and philosophy (Antubam, 1963). The ideal African woman is portrayed very plump which signifies that she is well fed. To be beautiful, she has to be plump and not slim. She should have broad hips and noticeable breasts (Ampaw, unpublished). The torso of the female beauty must appear oval with the large part of it tapering towards the neck. The thigh from the waist line to the bottom of the knee-cap should fall within an egg-shape with the wider part towards the waist. The leg from the centre of the knee-cap to the ground must also fall within the egg-shape with the wider part tapering towards the toes (Antubam, 1963). These different schools of thought (considering slim or plump figures as ideal beauty) lie in the eyes of the beholder. Irrespective of which school one belongs to, the rationale for comparing body measurements and/or proportions with the appropriate above-mentioned scenarios helps in the creation of an ideal silhouette.

In view of the need to create an ideal silhouette, a chart (Table 3) has been designed to facilitate how readers should analyze their figures in terms of actual measurements, general description of the figure, body assets and problems. The chart

Table 3: Personal Analysis Chart

\begin{tabular}{|c|c|c|c|c|}
\hline Figure & $\begin{array}{l}\text { Actual } \\
\text { Measurement }\end{array}$ & General Description & Assets & Problems \\
\hline Height & & Tall, average, short & & \\
\hline Weight & & Slender, average, overweight. & & \\
\hline Bust & & Prominent, average, small. & & \\
\hline Waistline & & Large, average, small, long, short. & & \\
\hline Derriere & & Flat, raised, dropped, & & \\
\hline Hips & & Wide, small, average. & & \\
\hline Legs & & $\begin{array}{l}\text { Long, short, saddle legs, very thin legs, heavy } \\
\text { legs, bowed legs. }\end{array}$ & & \\
\hline Thigh & & Heavy, average. & & \\
\hline Calf & & Thick, slender, well shaped. & & \\
\hline Ankle & & Thick, slender, average. & & \\
\hline \multirow{3}{*}{ Shoulders } & & Broader than hip and square, & & \\
\hline & & Broader than hips and sloping, & & \\
\hline & & Narrower than hips, & & \\
\hline Neck & & Short, long, thin, thick, average. & & \\
\hline $\begin{array}{l}\text { Arms and } \\
\text { hands }\end{array}$ & & $\begin{array}{l}\text { Unusually long, large, average, very thin, heavy } \\
\text { muscular }\end{array}$ & & \\
\hline
\end{tabular}


should be filled by providing accurate measurements and underlining the descriptions that apply to the figure in question. There will be the need to engage someone briefly to help with the body measurements, but the following should be taken note of:

1. Metal tape measure is not appropriate. Although it may be flexible, it will not conform to the body easily and will not give the best results

2. The measuring tape must be laid flat against the skin. It should not be pulled too tight or left too loose.

3. Pen or pencil and paper must be close by so that the measurement results could be written down as they are measured.

You should also summarize by listing your assets, the beautiful characteristics you would like to emphasize, and problems or liabilities you would like to improve or subordinate through clothing. For example, write height under assets if height is an asset to you and bust under problems if bust is a problem to you.

Now, you have qualities you like and features you dislike according to your philosophy of an

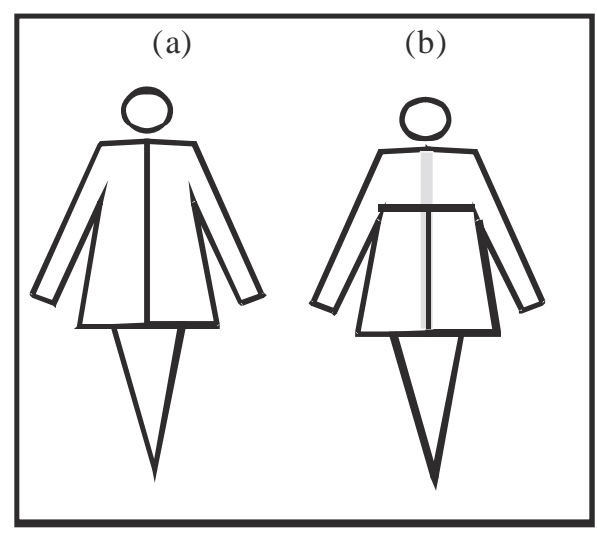

Fig. 1:

(a) Vertical line allows the eye to move along its axis without interruption.

(b) The eye can move from left to right when a vertical line is topped with a horizontal line thus, widening the figure. ideal beauty. Illusion can effectively stress your strong points and armour your weak points. To benefit from the effects of illusions, two rules should be followed (Rasband, 1994).

1. You should direct observer's eye to the interesting features on the body

2. Use the eyes' focal points to draw attention away from figure flaws.

These can be achieved through effective use of line, colour and texture in the following guiding principles:

\section{Effects of line}

By conventional definition, a line is the path left by a moving point. You put down your pencil on a sheet of paper and move its point across the paper to make a line. Line is so basic to art that it is difficult to conceive of any work of art not having lines.

The wise selection of line in clothing can create optical illusions to flatter your appearance using line in the garment silhouette and garment detail. Silhouette is the outline of the garment. Details include seam lines and garment features such as

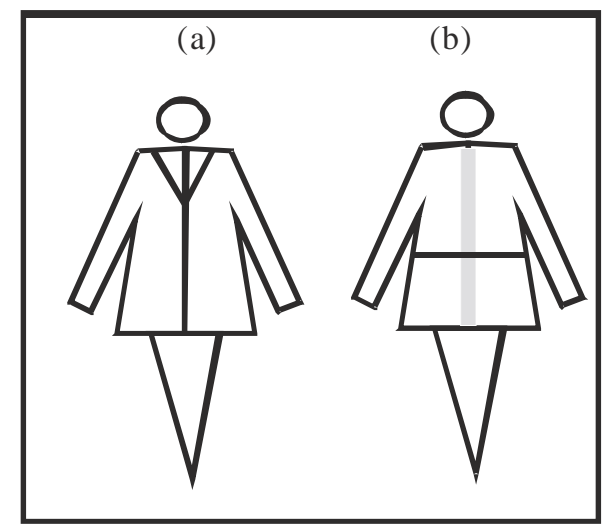

Fig. 2

(a) The magic " $Y$ " creates a feeling of height

(b) The sooner the eye encounters a horizontal line, the shorter the figure will appear.

138 Journal of Science and Technology, Vol. 28, No. 2, August, 2008 


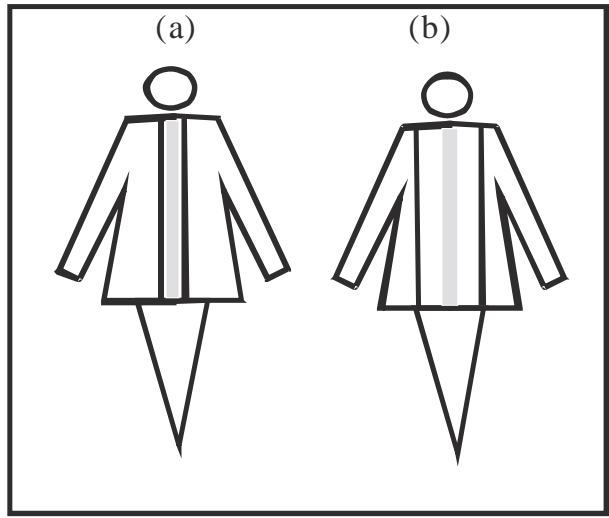

Fig. 3

(a) The closer the vertical lines, the slimmer the figure will appear.

(b) The wider the vertical lines, the broader the figure.

pockets, collars, belts, pleats, gathers, fabric prints, decorations and openings. Generally, vertical lines in attractive and eye-catching colours, which carry the eye up the figure without interruption, will give a taller and more slender illusion. Lines which stop the eye from traveling upward by moving the eye from side to side (e.g. horizontal lines) or back down will create a shorter and heavier illusion (Wright, 2001). Both the detail lines and the silhouette influence the optical illusion created when a garment is worn as shown in Figures 1-4.

\section{Effects of colour}

Colour is one of the first things people notice about clothing. The use of colour can create illusions of the figure size in the same way line does. White is more expansive than black. An apparel will look larger in a light colour whiles a dark colour appears to diminish an apparel. Monochromatic dressing is more slimming and elongating than dressing in contrasting colour blocks or pattern blocks. Solid colours tend to make you look thinner and taller, especially when the same colour is worn from head to toe.

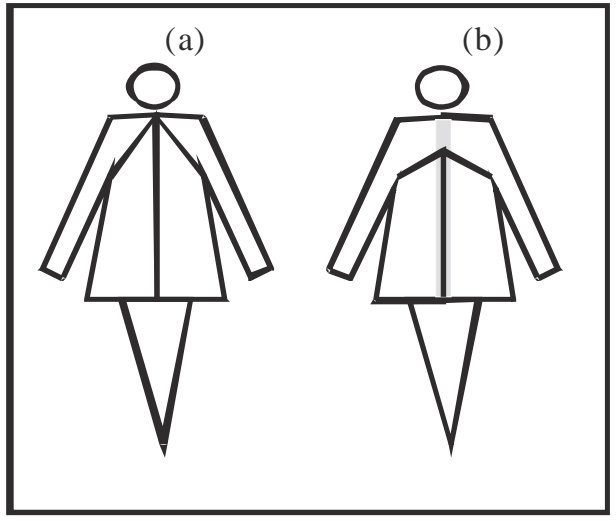

Fig. 4: Vertical line suddenly appears shorter when the eye is forced downward

Dividing the body into numerous colours can shorten and widen the body. To look taller and slimmer, avoid big prints and stick to solid colours. Black and white is the most dramatic colour combination because it has maximum value contrast (Noubikko, 2007).

\section{Effects of Texture}

The effects of texture in clothing influence how colours appear and how design lines function. Texture describes the body and surface of fabric. Textures may be rough or smooth, coarse or fine, crisp or clingy, soft or stiff, thin or bulky, opaque or sheer, shiny or dull, heavy or light or any combination of these characteristics (Wright, 2001). Soft and clingy textures reveal the figure and emphasize figure irregularities. Stiff and crisp texture stand away from the body and hide figure irregularities. Bulky textures seem to add volume to the figure. Small figures are overpowered by these textures. Dull finishes absorb light and generally make the figure look smaller. Shinny fabrics make the figure appear larger and reveal figure irregularities. Coarse or rough fabrics are good choices for average to slim figures. They add volume to large figures and overpower small figures. Smooth (not shiny) fabrics hide figure 
irregularities and are attractive on most figure types.

\section{RECOMMENDATIONS}

Using the effects of line, colour and texture in camouflaging figure flaws, and stressing strong points, the following alternative design ideas have been recommended for the respective physical characteristics.

\section{Petite woman}

Petite woman is small and thin. She needs to keep clothes in line, slim narrow belts. She should have vertical patterns or vertical seaming to make her appear taller. One colour or a slight contrast in colours will flatter her endlessly. Also, fabrics that are soft and flowing should fit well. Solid prints rather than large, splashy prints are good.

\section{Tall woman}

Tall woman can indulge in wide belts; avoid tight clothes and skirts that are too short or too long. If your height is more than what you want avoid heels and minimize use of padding on your shoulders. If you are very thin, fullness and shortness are your tricks of illusion. Also, wear horizontally striped designs and patterns to counteract the effect of tallness which may seem superfluous.

\section{Large bust}

The goal is to divert the eye downward to balance the bust with the rest of your body. Wear slender trousers and skirts for a slim silhouette, and pick tops that are a little loose in dark colours. You can also lead the eye away with pretty collars, subtly gathered shoulders, or with colours that flatter and draw attention to your face and eyes. Try to avoid belts for they will cut you in half and keep the focus on your chest.

\section{Tiny bust}

Soft shirring from the shoulder lines or from yokes is advisable. Details such as tucking, gathers, simple layered embroidery, pockets and light colour on top create a bigger bust silhouette. Padded, capped, wide collars and ruffle fronts can balance your figure.

\section{Broad shoulders}

$\mathrm{V}$-neck tops will break the visual line of the shoulders and make them look narrow. Wear a darker colour top and a lighter colour bottom. Look for bottoms that balance your shoulder line. Fuller skirts, wide-legged trousers, etc. will help create a balance line and help your waist look narrow. Avoid broad-shouldered tops (like one without shoulder pads) and double-breasted jackets, both of which emphasize the shoulder line and draw a lot of attention to the top of your body.

\section{Narrow shoulders}

Narrow collars and lapels, raglan sleeves, kimono sleeves, flared peplums are good. Padded shoulders can balance with horizontal lines in skirt.

\section{Large hips}

A woman with large hips can use clothes with vertical lines to make an up and down illusion. Clothes with small padded shoulders should be chosen. Wear long tops that go pass your hips. Lighter colours on top can be worn. This brings eyes up. Choose accessories close to the same colour clothes you are wearing including shoes. This gives your body an unbroken slimmer look. Stay with straight skirts.

\section{Narrow hips}

Soft front fullness such as gathers, pleats and frills are pleasing designs to widen the hip line. Skirts should have details including large patterns and horizontal lines.

\section{CONCLUSION}

Fitted and distinct clothes should be the concern of all because it is a means of self-expression. Although the study was conducted with limited population the outcome is significant for majority of people who are assumed to possess similar ideas, characteristics and philosophies and for 
which matter they can also benefit immensely. It is always better to wear one interesting outfit than several other different outfits. One thing makes one best statement about your personality, and too many things make too many statements. You should never get worried about wearing the same line all the time, if that is the most flattering line for you. You can get variety through fabric, colour and detail. No one notices the line of your outfit if it looks good, but people invariably notice clothes that are unflattering.

\section{REFERENCES}

Antubam, K. (1963). Ghana's Heritage of Culture, Kochler and Amelang, Leipzig, pp. 8993

Corley, C. F. (2007). Dress for Success, Career Services, Sacramento City College, New Zealand, pp. 1-10.

Hazen, G. G. (1998). Fantastic Fit for Everybody, Rodale Press, USA, p. 10.
Jackson, C. (1980). Colour Me Beautiful, First Ballantine Books Edition, USA, p. 96.

Natural History Magazine (1980). Measurements from Bureau of Home Economics, United States Department of Agriculture, p. 18.

Noubikko, (2007). Body Camouflage, Noubikko Corporation, USA, p. 2.

Rasband, J. (1994). Fabulous Fit, Fairchild Press, USA, p. 80.

Women's Measurements for Garment and Pattern Construction, Miscellaneous Publication 454 (1985). United States Department of Agriculture, p. 27.

Wright, S. (2001). Extension Clothing and Textiles Management, New Mexico State University, USA, pp. 1-4. 